\title{
The influence of adding modified zirconium oxide-titanium dioxide nano-particles on mechanical properties of orthodontic adhesive: an in vitro study
}

Nayef H. Felemban ${ }^{1,3^{*}}$ and Mohamed I. Ebrahim ${ }^{2}$

\begin{abstract}
Background: The purpose of this in-vitro study was to examine the effect of incorporating different concentrations of Zirconium oxide-Titanium dioxide ( $\mathrm{ZrO2}-\mathrm{TiO} 2)$ nanoparticles, which can have antibacterial properties, on the mechanical properties of an orthodontic adhesive.

Methods: ZrO2-TiO2 (Zirconium oxide, HWNANO, Hongwu International Group Ltd, China) -Titanium dioxide, Nanoshell, USA) nanopowder were incorporated into orthodontic adhesive (Transbond XT, 3 M Unitek, Monrovia, USA) with different concentrations ( $0.5 \%$ weight nonofiller and $1 \%$ weight nanofiller). The size of nanoparticle was $70-80 \mathrm{~nm}$ for $\mathrm{ZrO} 2$ and less than $50 \mathrm{~nm}$ for TiO2. For measuring the shear bond strength of the three groups of orthodontic adhesives [Transbond (control), Transbond mixed with 0.5\% weight ZrO2-TiO2, and Transbond mixed with 1\% weight ZrO2-TiO2], 30 freshly extracted human first premolars were used and bonded with stainless steel metal brackets (Dentaurum ${ }^{\oplus}$, Discovery ${ }^{\circledR}$, Deutschland), using the 3 orthodontic adhesives and 3 M Unitek; Transbond TM Plus Self-Etching Primer (10 samples in each group). The recorded values of compressive strength and tensile strength (measured separately on 10 samples of orthodontic adhesives (add the $3 \mathrm{D}$ size of sample, light cured for $40 \mathrm{~s}$ on both sides) of each orthodontic adhesives), as well as the shear bond strength in Mega Pascal unit (MPa) were collected and exposed to one-way analysis of variance (ANOVA) and Tukey's post-hoc tests.
\end{abstract}

Results: orthodontic adhesive with $1 \%$ weight $\mathrm{ZrO} 2-\mathrm{TiO} 2$ showed the highest mean compressive $(73.42 \pm 1$. $55 \mathrm{MPa}, \mathrm{p}: 0.003, \mathrm{~F}: 12.74)$, tensile strength $(8.65 \pm 0.74 \mathrm{MPa}, \mathrm{p}: 0.001, \mathrm{~F}: 68.20)$, and shear bond strength (20.05 \pm 0 . $2 \mathrm{MPa}$, p: 0.001, F: 0.17).

Conclusions: Adding $\mathrm{ZrO} 2-\mathrm{TiO} 2$ nanoparticle to orthodontic adhesive increased compressive strength, tensile strength, and shear bond strength in vitro, but in vivo studies and randomized clinical trials are needed to validate the present findings.

Keywords: Orthodontic adhesives, Titanium dioxide, Zirconium oxide

\footnotetext{
* Correspondence: nfelemban@tudent.edu.sa; nfelemban@yahoo.com

${ }^{1}$ Orthodontic department, Faculty of Dentistry, Taif University, Taif, Saudi

Arabia

${ }^{3}$ P.O.B. 4302, Makkah 21955, Saudi Arabia

Full list of author information is available at the end of the article
} 


\section{Background}

Failure in the bonding system of orthodontic brackets will lead to frequent debonding of orthodontic brackets that delays treatment results. Several tooth- or materialrelated factors can affect the bonding systems and the failure rates of orthodontic brackets; about $5-7 \%$ of clinical bond failures occur for different reasons [1, 2].

Shear bond strength of orthodontic composite resin is greater than resin-modified glass-ionomer cement and polyacid-modified composite resin [3]. Other studies show that shear bond strength was not significantly different when tested over a period of time after orthodontic brackets bonding [4].

In order to improve the properties of resin-based composite, previous studies have focused on the pretreatment of inorganic fillers [5, 6], resin monomers [7], and the development of curing methods. Heat-curing and post-curing heat treatments both increase the degree of polymerization and improve the composite strength to some extent [8]. Nanofillers and fibers have been proposed as reinforcing fillers in dental composite, adding these fillers and fibers will result in increase in composite strength [9].

With the great development of nanotechnology and Nano-phased materials, much attention is directed toward the use of Nano-sized fillers to reinforce the denture base resins, thus producing a polymer nanocomposite with improved mechanical and physical properties as compared to those filled with micro-scale particles; furthermore, the use of multiple Nano fillers rather than a single additive develops a high performance composite that cannot be achieved by using a single filler [10]. The mechanical properties of the resultant polymer nanocomposite depend strongly on the dispersion and adhesion of the filler at the filler matrix interface, thus surface treatment of the fillers with a silane coupling agent is necessary to improve compatibility between the filler and matrix [11].

Both Zirconium oxide $\left(\mathrm{ZrO}_{2}\right)$ and Titanium dioxide $\left(\mathrm{TiO}_{2}\right)$ nanoparticles have interesting mechanical, physical, and photocatalystic properties that make them suitable additives; furthermore, many properties of these mixed nanostructured-metal oxides $\left(\mathrm{ZrO}_{2}: \mathrm{TiO}_{2}\right)$ were reported to be better than single additives mainly due to the size difference between titanium and zirconium [12].

Several antibacterial components have been added to dental composite resin and adhesive system to disinfect the area around the adhesive restorations for a prolonged duration such as dodecylamine, bipyridine, tannic acid derivatives, polyhexanide, amphilic lipids, silver, Chlorhexide gluconate and fluorides, also incorporating $\mathrm{TiO}_{2}$ to orthodontic adhesive can enhance antibacterial effect and decrease surface roughness of orthodontic adhesives [13].

The objective of this study was to evaluate the effect of incorporation of $\mathrm{ZrO}_{2}-\mathrm{TiO}_{2}$ Nano fillers which can have antibacterial effect on mechanical properties of orthodontic adhesive; compressive strength, tensile strength, and shear bond strength.

The null hypothesis was that there was a statistically significant deference between mean values of compressive, tensile and shears bond strengths in orthodontic adhesive after adding $\mathrm{ZrO}_{2}-\mathrm{TiO}_{2}$ Nano fillers in deferent concentrations.

\section{Methods}

All materials that been used in the study with manufacturer information are listed in Table 1.

\section{Surface modification of nano fillers}

Introducing the reactive groups onto the surface of Nano fillers was achieved by their action of the trimethoxysilylpropyl methacrylate (TMSPM) silane coupling agent with the Nano fillers using 5\% weight (wt.) of TMSPM for surface modifications of $\mathrm{ZrO}_{2}$ nanoparticles and 75\% wt. of TMSPM for surface modifications of $\mathrm{TiO}_{2}$ nanofillers [14]. $\mathrm{ZrO}_{2}$ and $\mathrm{TiO}_{2}$ (1:1) Nano fillers by weight were added into dental adhesive used in orthodontics with different concentrations ( 1 and $0.5 \%$ respectively).

\section{Preparation of modified adhesives}

To achieve dental adhesives containing 10\% nanoparticles, $64 \mathrm{mg}$ nanopowder was blended into $576 \mathrm{mg}$ (Transbond $^{\mathrm{TM}}$ XT Light Cure Adhesive composite, $3 \mathrm{M}$ Unitek), using a mixing spatula on a glass slab in a semidark environment until a uniform consistency was achieved. Two hundred mg of the $10 \%$ wt. blended composite was then mixed with $200 \mathrm{mg}$ of the original composite to obtain $0.5 \%$ wt. containing composite, similarly, $40 \mathrm{mg}$ of $10 \%$ composite was blended with $360 \mathrm{mg}$ original composite for the $1 \% \mathrm{w} / \mathrm{w}$ composite [15]. After mixing the particles with composite the resultant composite is passed through two roll mills for about five minutes in a mastication stage, for better distribution of nanoparticles in the matrix [16].

\section{Grouping of the specimens}

A total of 60 specimens were used in this study. The specimens of orthodontic adhesive were divided into three main groups (20 specimens each) according to the percentage of $\mathrm{ZrO}_{2}-\mathrm{TiO}_{2}$ nanopowder that was added to the dental adhesive with concentrations $0.5 \%$, $1 \%$ and control group without any additive. Every group was further subdivided into two subgroups (10 specimens each) according to the type of test as shown in Table 2, Figs. 1 and 2. 
Table 1 Materials

\begin{tabular}{llll}
\hline & Materials & Trade & Manufacturer \\
\hline 1 & Zirconium oxide (ZrO2) nanofiller 70-80 nm & HWNANO & China \\
2 & Titanium oxide (TiO2) Nanofiller $<50 \mathrm{~nm}$. & Nanoshell & USA \\
3 & Trimethoxysilylpropyl methacrylate 98\%Silane & No 2530- 85-8. & Sigma- Aldrich (Germany) \\
4 & Orthodontic Adhesive & Transbond XT, Adhesive composite 3 M Unitek, Monrovia & USA \\
\hline
\end{tabular}

\section{Compressive strength}

\section{Mold construction}

$4 \mathrm{~mm}$ diameter by $6 \mathrm{~mm}$ height cylindrical Teflon mold was fabricated according to the International Standards Organization (ISO) No. 9917 (2000).

\section{Specimens preparation}

The orthodontic Adhesive was condensed in the Teflon mold, which was then placed on a glass plate according to each group. Specimens were covered with celluloid strips and pressed with another glass plate. All of the specimens were exposed to light cure for $40 \mathrm{~s}$ from both sides (BGlight-LTD, 4002 Plovdiv, 430-490 nm, Bulgaria). The specimens were stored in distilled water for $24 \mathrm{~h}$ prior to testing. Curing radiometer equipment (LI-189.Li-Cor Inc, Lincoln, NE68504, USA) was used to ensure steady light intensity throughout the polymerization of all specimens.

\section{Compressive strength testing}

Specimens were loaded on the Lloyd mechanical testing machine (model LRX plus II, Fareham, England) at crosshead speed of $0.5 \mathrm{~mm} / \mathrm{min}$. The specimens were placed with flat ends vertically laid between the two metal plates.

The load was applied until the specimen was crushed; the peak force required to fracture each specimen was recorded in Newton from the stress-strain curve. The compressive strength was calculated in Mega Pascal $(\mathrm{MPa})$ using the following equation:

$$
\text { Compressive Strength }=4 \mathrm{P} / \pi \mathrm{d}
$$

Where $(\mathrm{P})$ is the load at the fracture point in Newtons and $\mathrm{d}$ is the diameter of the specimen.

\section{Diametric tensile strength}

Measuring the tensile strength of orthodontic adhesive is done using an indirect tensile test, a compressive load is placed on the diameter of a cylindrical specimen. The compressive stress induces a tensile stress in the plane of the application of the force. The tensile stress is directly proportional to the compressive load.

In this test, the specimen cylinder was mounted on the Lloyd mechanical testing machine and the load was applied to the specimen using a crosshead speed of $0.5 \mathrm{~mm} / \mathrm{min}$ applying a compressive force on the specimen until fracture. The diametric tensile strength was calculated in $(\mathrm{MPa})$ using the following equation:

\section{Diametric Tensile Strength $=2 \mathrm{P} / \pi \mathrm{dt}$}

Where $(\mathrm{P})$ is the load at the fracture point in Newtons, (d) is the diameter of the specimen, and (t) is the thickness of the specimen.

\section{Shear bond strength}

Thirty freshly extracted, human maxillary first premolars for orthodontic reasons were collected and stored in a solution of $0.1 \%$ thymol. The criteria for tooth selection included intact buccal enamel, not subjected to any pretreatment chemical agents, no cracks, and no caries [17]. The teeth were placed and mounted in metal rings using cold-cure acrylic resin and numbered randomly; then the teeth were polished for $10 \mathrm{~s}$ with non-fluoridated pumice using prophylactic rubber cups [18-20].

Metal brackets (Dentaurum ${ }^{\circledast}$, Discovery ${ }^{\circ}$ ) of maxillary first premolars with an average base surface area of $10.5 \mathrm{~mm}^{2}$ were used in this study. Then the teeth were randomly

Table 2 Orthodontic adhesive groups

\begin{tabular}{llll}
\hline Groups & Group description & Type of test & Quantity \\
\hline Group A & Orthodontic adhesive without any additives (control group) & -Compressive and tensile strength & -10 specimens \\
Group B & Orthodontic adhesive with 0.5\% wt. & - Shear bond strength & -10 specimens \\
& ZrO2-TiO2 nanofillers. & -Compressive and tensile strength & -10 specimens \\
Group C & Orthodontic adhesive with 1\% wt. & - Shear bond strength & -10 specimens \\
& ZrO2-TiO2 nanofillers & -Compressive and tensile strength & -10 specimens \\
Total & & - Shear bond strength & -10 specimens \\
\hline
\end{tabular}




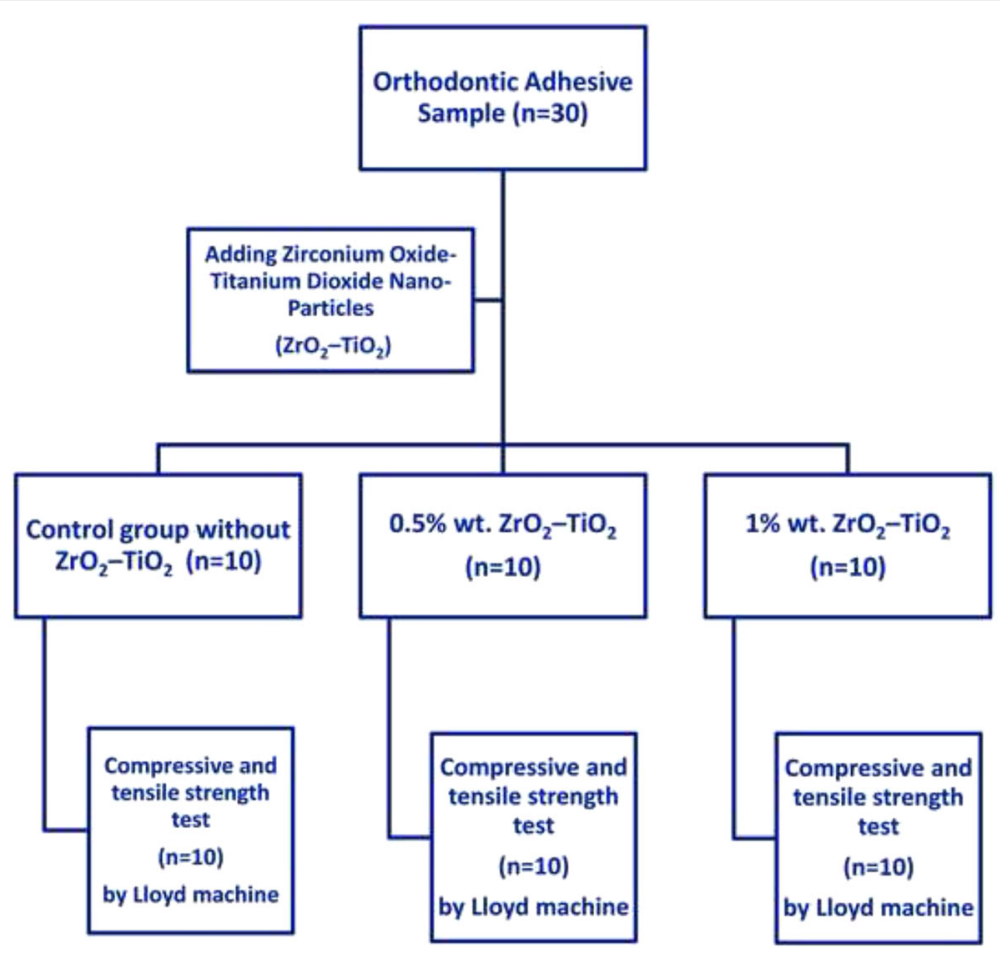

Fig. 1 Flow diagram of specimens groups for compressive and tensile strength tests

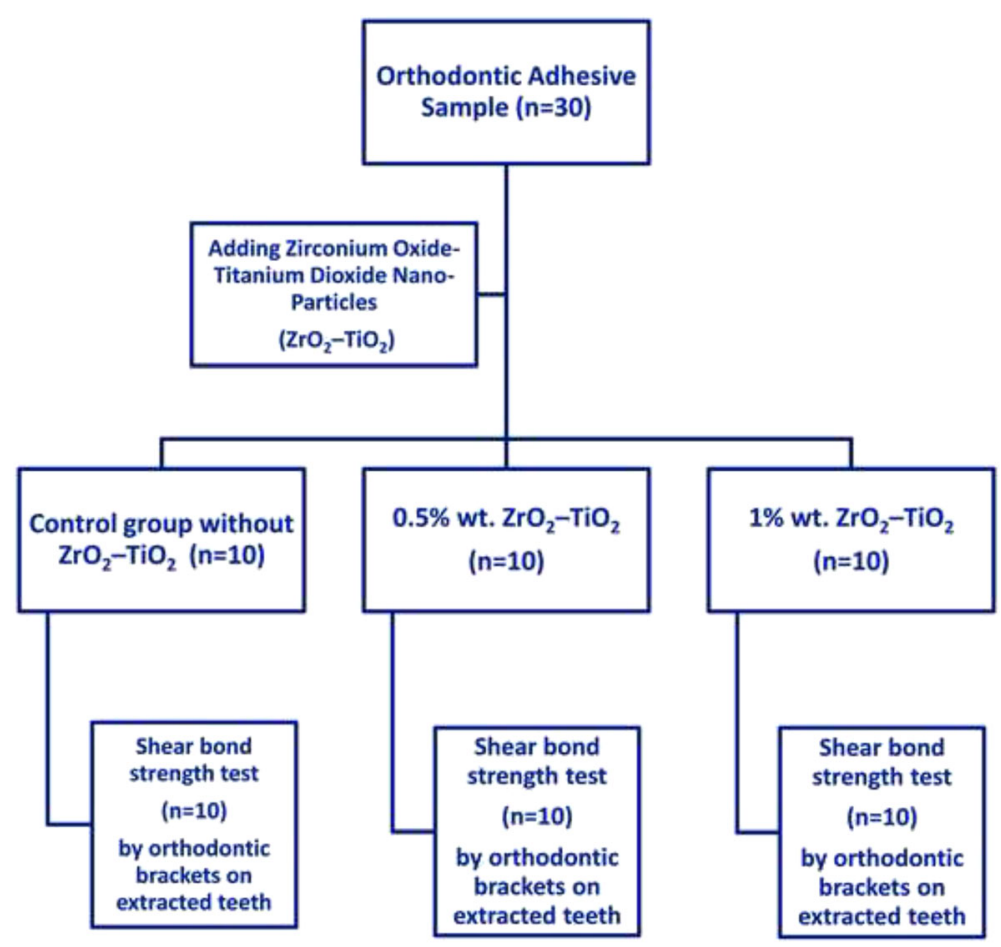

Fig. 2 Flow diagram of specimens groups for shear bond strength test 
divided into three groups, each consisting of 10 teeth, and bonded as shown in Table 2 (groups A, B and C).

The groups were bonded using $3 \mathrm{M}$ Unitek; Transbond ${ }^{\mathrm{m}}$ Plus Self-Etching Primer one bottle, which was applied for $20 \mathrm{~s}$ then dried with mild air flow, then light cured for $10 \mathrm{~s}$.

Group A (the control group), the orthodontic brackets bonded to the tooth surface using Transbond ${ }^{\text {Twt }}$ XT Light Cure Adhesive.

Groups B and C, the orthodontic brackets bonded to the tooth surface using the modified adhesive as described in Table 2.

The specimens were immersed in $37{ }^{\circ} \mathrm{C}$ water for $24 \mathrm{~h}$, and then subjected to thermo-cycling to simulate clinical thermal stress conditions before testing. These directions are according to the American National Standards Institute/American Dental Association (ANSI/ADA) [21], and International Organization for Standardization (ISO) [22] for direct filling resins and dental adhesion.

All specimens were subjected to thermo-cycling by being stored alternatively in water reservoirs at $5{ }^{\circ} \mathrm{C}$ and $55{ }^{\circ} \mathrm{C}$, respectively, remaining in each reservoir for $30 \mathrm{~s}$ [23].

\section{Shear bond strength testing}

Shear bond strength testing was done using a Lloyd universal testing machine. Upper attachment knife-edge was used; Plastic cylinders with embedded teeth and brackets were mounted on a joint (lower attachment) and aligned in the testing apparatus to ensure consistency for the point of force application and direction of the debonding force for all specimens.

The direction of the debonding force was parallel to the enamel surface in an occlusal-gingival direction. The load was applied perpendicular to the interface of the tooth and bracket at a crosshead with speed of $0.5 \mathrm{~mm} / \mathrm{min}$ until debonding occurred.

The shear bond strength in $\mathrm{kg} / \mathrm{cm}^{2}$ was calculated based on the following equation:

\section{Shear Bond Strength $=\mathrm{P} / \pi \cdot \mathrm{r}^{2}$}

Where $(\mathrm{P})$ is shear load in kilograms, $(\mathrm{r})$ is the radius of the specimen in millimeter.

Then the shear bond strength was converted to $\mathrm{MPa}$ by multiplying the results by 0.09807 .

The recorded values of compressive, tensile, and shear bond strength in $(\mathrm{MPa})$ were collected, and statistically analyzed. One-way analysis of variance (ANOVA) and Tukey's tests were used for testing the significance between the means of tested properties of all tested materials. This was statistically significant when the $P$ value $\leq 0.05$.

\section{Results}

The comparison between mean compressive strengths in (MPa) is shown in Table 3, comparison between mean tensile strengths in ( $\mathrm{MPa})$ is shown in Table 3, and comparison between mean shear bond strengths in $(\mathrm{MPa})$ is shown in Table 4.

All groups of orthodontic adhesive with nanoparticles (B and C) showed compressive strength, tensile strength, and shear bond strength values higher than that of the control group (A).

The power analysis revealed that a total sample size of 30 (10 per group) was needed to detect clinically meaningful differences between the groups at a power of $85 \%$ and at 0.05 significance level.

\section{Compressive and tensile strengths}

Orthodontic adhesive specimens with $\mathrm{ZrO}_{2}-\mathrm{TiO}_{2}$ Nano fillers (groups $\mathrm{C}$ and $\mathrm{B}$ ) showed significantly high compressive and tensile strengths when compared with the control group, while the increase in compressive and tensile strengths was not significant between Group C (1\% wt. $\left.\mathrm{ZrO}_{2}-\mathrm{TiO}_{2}\right)$ and Group B $\left(0.5 \%\right.$ wt. $\left.\mathrm{ZrO}_{2}-\mathrm{TiO}_{2}\right)$.

\section{Shear strength}

Table 4 shows the comparison between the mean shear bond strength of three tested groups. Orthodontic

Table 3 Comparison between mean compressive and tensile strength in (MPa) of adhesive groups

\begin{tabular}{|c|c|c|c|c|c|c|c|c|}
\hline Groups & Nanoparticle percent & $\mathrm{N}$ & Range & Mean (SD) & $95 \% \mathrm{Cl}$ & $\mathrm{F}$ & $p$-value & $\begin{array}{l}\text { Tukey } \\
\text { post Hoc }\end{array}$ \\
\hline \multicolumn{9}{|c|}{ Compressive strength } \\
\hline Group A & without nanofillers & 10 & $53.65-57.23$ & $54.92(4.15)$ & $53.6-55.3$ & 12.74 & 0.003 & Group C < Group A, Group B < Group A \\
\hline Group B & 0.5 wt $\%$ & 10 & $65.96-72.68$ & $69.28(3.76)$ & $68.0-70.5$ & & & \\
\hline Group C & 1 wt \% & 10 & $69.33-76.58$ & $73.42(1.55)$ & $71.7-74.2$ & & & \\
\hline \multicolumn{9}{|c|}{ Tensile strength } \\
\hline Group A & without nanofillers & 10 & $2.21-6.38$ & $4.92(0.54)$ & $4.1-5.7$ & 68.20 & 0.001 & Group C < Group A \\
\hline Group B & 0.5 wt $\%$ & 10 & $6.54-8.35$ & $6.14(0.71)$ & $5.1-6.5$ & & & \\
\hline Group C & 1 wt \% & 10 & $7.42-9.64$ & $8.65(0.74)$ & $7.8-8.5$ & & & \\
\hline
\end{tabular}

$N$ Number of sample, $\mathrm{Cl}$ Confidence interval, SD Standard deviation 
Table 4 Comparison between mean shear bond strength in (MPa) of adhesive groups

\begin{tabular}{cllllllll}
\hline S hear bond strength & \multicolumn{1}{l}{} \\
\hline Groups & Nanoparticle percent & $\mathrm{N}$ & Range & Mean (SD) & $95 \% \mathrm{Cl}$ & $\mathrm{F}$ & $p$-value & Tukey Post Hoc \\
\hline Group A & without nanofillers & 10 & $13.21-16.79$ & $14.75(0.25)$ & $13.6-15.1$ & 0.17 & 0.001 & Group C< Group A, Group B < Group A \\
Group B & 0.5 wt \% & 10 & $18.34-22.41$ & $20.32(0.47)$ & $19.4-20.9$ & & & \\
Group C & 1 wt \% & 10 & $23.22-27.58$ & $25.05(0.2)$ & $14.3-20.3$ & & & \\
\hline
\end{tabular}

$N$ Numb er of sample, $\mathrm{Cl}$ Confide nce interval, SD S tandard deviat ion

adhesive specimens with $1 \%$ wt. $\mathrm{ZrO}_{2}-\mathrm{TiO}_{2}$ Nano fillers (Group C) showed a significantly highest shear bond strength followed by the orthodontic adhesive specimen with $0.5 \%$ wt. $\mathrm{ZrO}_{2}-\mathrm{TiO}_{2}$ Nano fillers (Group B), while the control group was significantly lowest shear bond strength.

Therefore the null hypothesis that compares the compressive, tensile and shears bond strengths after adding $\mathrm{ZrO}_{2}-\mathrm{TiO}_{2}$ Nano fillers to orthodontic adhesive was accepted and not rejected in this study.

\section{Discussion}

Several factors, such as failure in the bonding technique, low retentiveness of certain bracket bases, masticatory forces, and reduced size of the bracket base for esthetic reasons, can result in bracket debonding [24, 25] that will prolong the treatment time and increase the treatment costs. Several solutions had been proposed, such as aluminum-oxide sand blasting and primer application [26], to minimize the unwanted debonding rates in this study by adding $\mathrm{ZrO}_{2}-\mathrm{TiO}_{2}$ to orthodontic adhesive. The results showed an increase in the shear bond strength (20.32 and $25.05 \mathrm{MPa})$, although 5.9 to 7.5 $\mathrm{MPa}$ is the minimum acceptable shear bond strength for routine clinic use, as considered by Reynolds [27], we don't always have an ideal situation for bonding brackets and up to $21 \mathrm{MPa}$ shear bond strength is acceptable for orthodontic treatment. The failure rate of brackets with Transbond ${ }^{\mathrm{Tm}}$ Plus range from $0.94 \%$ to $7.4 \%$ [28-31].

In this study, the self-etching primer had been applied for $20 \mathrm{~s}$ prior to the process of light curing (unlike the manufacturer's instructions) which would yield superior performance of the etching primer. This was done by prolonging the application time, as shown by dos Santos,et al [29].

In order to simulate the mastication forces that create stresses to the restoration materials a compressive strength test are used in laboratory experiments [32]. Most mastication forces are not constant and the exact values are not known [33].

Measuring the shear bond strength for bonded orthodontic brackets is very common in literatures, it is a simple test when compared to tensile bond strength tests, in which it is difficult to align the specimen in the testing machine without creating deleterious stress distributions [34, 35].

Titanium dioxide $\left(\mathrm{TiO}_{2}\right)$ nanofiller has an antibacterial effect, biocompatibility and minimum toxicity. This nanofillers beside their antibacterial effect they have been suggested as reinforcing fillers [36, 37].

Zirconium oxide $\left(\mathrm{ZrO}_{2}\right)$ was used because it has excellent biocompatibility and white color which is less likely to alter its esthetic. The nanofiller particles were used in this study as they yield a better dispersion, eliminate aggregation, and improve its compatibility with organic polymer [38].

Both $\mathrm{ZrO}_{2}$ and $\mathrm{TiO}_{2}$ nanoparticles were reported to be better than single additives mainly due to the size differences between titanium and zirconium [12]. In this study, compressive, tensile, and shear bond strength improvement of orthodontic adhesive containing $1 \%$ and $0.5 \%(\mathrm{w} / \mathrm{w}) \mathrm{ZrO}_{2}-\mathrm{TiO}_{2}$ nanoparticles can be attributed to the small sizes of the $\mathrm{ZrO}_{2}$ and $\mathrm{TiO}_{2}$ and also to the surface modification of the nanofillers with TMSPM coupling agents which provide better dispersion of particles in matrix, avoid agglomeration, and improves interfacial adhesion of the fillers to the polymer matrix [39].

Shear bond strength can be $40 \%$ less when measured in vivo than in vitro and this makes our results in shear bond strength higher than what will be in real clinical cases, adding $\mathrm{ZrO}_{2}-\mathrm{TiO}_{2}$ nanoparticles can enhance the shear bond strength for optimum clinical use, further in vivo studies are needed [40].

Color stability, polymerization shrinkage, antibacterial effect and toxicity of adding $\mathrm{ZrO}_{2}-\mathrm{TiO}_{2}$ nanoparticles on resin-based adhesives could be studied in the future with other mechanical and physical properties in different concentrations of Nano filler.

\section{Conclusions}

On the basis of this study, we can conclude that the addition of $\mathrm{ZrO}_{2}-\mathrm{TiO}_{2}$ nanoparticles on resin-based adhesives increase the compressive, tensile, and shear bond strengths of the adhesive in vitro.

\section{Abbreviations}

MPa: Mega pascal; N: Newton; RBC: Resin-based composite; $\mathrm{TiO}_{2}$ : Titanium dioxide; Wt.: Weight; $\mathrm{ZrO}_{2}$ : Zirconium oxide; $\mathrm{ZrO}_{2}-\mathrm{TiO}_{2}$ : Zirconium oxide-titanium dioxide 


\section{Acknowledgements}

We would like to show our gratitude and thanks to Dr. Roshan Noor Mohamed (assistant professors, preventive dentistry department, faculty of dentistry, Taif University) and Dr. Sakeenabi Basha (assistant professors, preventive dentistry department, faculty of dentistry, Taif University) for sharing their help and assistance in statistical analysis for this research.

\section{Funding}

Not applicable.

\section{Availability of data and materials}

The data from this study can be requested from the corresponding author at: nfelemban@tudent.edu.sa, Individuals who are interested in accessing study data should submit a written request outlining their aims and analytical plans in obtaining and using the data with an address, contact and e-mail information for tracking purposes. The information provided to users should not be used for commercial purposes, and should not be distributed to third parties.

\section{Authors' contributions}

NF participated in the design of the study, helped in data collection and drafted the manuscript. ME collected the data, performed the statistical analysis, and helped draft the manuscript. Both authors read and approved the final manuscript.

\section{Competing interest}

The authors declare that they have no competing interests.

\section{Consent for publication}

Not applicable.

\section{Ethics approval and consent to participate}

All extracted teeth had been extracted for orthodontic treatment not for research purposes, collection of extracted teeth had been done after the approval of ethical committee in faculty of dentistry, Taif University.

\section{Author details}

'Orthodontic department, Faculty of Dentistry, Taif University, Taif, Saudi Arabia. ${ }^{2}$ Restorative dentistry department, Faculty of Dentistry, Taif University, Taif, Saudi Arabia. ${ }^{3}$ P.O.B. 4302, Makkah 21955, Saudi Arabia.

Received: 7 May 2016 Accepted: 6 January 2017

Published online: 13 January 2017

\section{References}

1. O'Brien KD, Read MJ, Sandison RJ, Roberts CT. A visible light-activated direct-bonding material: an in vivo comparative study. Am J Orthod Dentofacial Orthop. 1989;95:348-51.

2. Bakhadher W, Halawany $\mathrm{H}$, Talic N, Abraham N, Jacob V. Factors affecting the shear bond strength of orthodontic brackets-a review of in vitro studies. Acta med (Hradec Králové. 2015;58(2):43.

3. Rix D, Foley TF, Mamandras A. Comparison of bond strength of three adhesives: composite resin, hybrid GIC, and glass-filled GIC. Am J Orthod Dentofacial Orthop. 2001;119:36-42.

4. Hajrassie MK, Khier SE. In-vivo and in-vitro comparison of bond strengths of orthodontic brackets bonded to enamel and debonded at various times. Am J Orthod Dentofacial Orthop. 2007;131:384-90.

5. Ruddell DE, Maloney MM, Thompson JY. Effect of novel filler particles on the mechanical and wear properties of dentalcomposites. Dent Mater. 2002;18:72-80.

6. Xu HH, Quinn JB, Smith DT, Antonucci JM, Schumacher GE, Eichmiller FC. Dental resin composites containing silica-fused whiskers - - effects of whisker-to-silica ratio on fracture toughness and indentation properties Biomaterials. 2002;23:735-42.

7. Lu H, Stansbury JW, Nie J, Berchtold KA, Bowman CN. Development of highly reactive mono- (meth) acrylates as reactive diluents for dimethacrylate-based dental resin systems. Biomaterials. 2005;26:1329-36.

8. Loza-Herraro MA, Rueggeberg FA, Caughman WF, Schuster GS, Lefebvre CA, Gardner FM. Effect of heating delay on conversion and strength of a post-cured resin composite. J Dent Res. 1998;77:426-31.
9. Bayne SC. Mechanical property analysis of two admixed PRIMM-modified commercial dental composites. Acad Dent Mater Trans. 1996;9:238.

10. Aly AA, Zeidan EB, Alshennawy AA, El-Masry AA, Wasel WA. Friction and wear of polymer composites filled by nano-particles: a review. World I Nanosci Eng. 2012;2:32-9.

11. Asar NV, Albayrak H, Korkmaz T, Turkyilmaz I. Influence of various metal oxides on mechanical and physical properties of heat-cured polymethylmethacrylate denture base resins. J Adv Prosthodont. 2013;5:502-6.

12. Tomar $\sqcup$, Chakrabarty BS. Synthesis, structural and optical properties of TiO 2ZrO 2 nanocomposite by hydrothermal method. Adv Mat Lett. 2013:4(1):64-7.

13. Borzabadi-Farahani A, Borzabadi E, Lynch E. Nanoparticles in orthodontics, a review of antimicrobial and anti-caries applications. Acta Odontol Scand. 2014:72(6):413-7.

14. Chaijareenont P, Takahashi H, Nishiyama N, Arksomnukit M. Effect of different amounts of 3-methacryloxypropyltrimethoxysilane on the flexural properties and wear resistance of alumina reinforced PMMA. Dent Mater J. 2012;31:623-8.

15. Mirhashemi A, Bahador A, Kassaee M, Daryakenari G, Ahmad-Akhoundi M, Sodagar A. Antimicrobial effect of nano-zinc oxide and nano-chitosan particles in dental composite used in orthodontics. J Med Bacteriol. 2015;2(3-4):1.

16. Yekrangi A, Afrasiabi M, Langari A, Hafshejani MK. Investigation of abrasion and morphology of rubber/nano titanium oxide nanocomposites. ARPN J Eng Appl Sci. 2014;9:580-5.

17. Bishara SE, Oonsombat C, Soliman MM, Warren JJ, Laffoon JF, Ajlouni R. Comparison of bonding time and shear bond strength between a conventional and a new integrated bonding system. Angle Orthod. 2005;75(2):237.

18. Saito K, Sirirungrojying S, Meguro D, Hayakawa T, Kasai K. Bonding durability of using self-etching primer with 4-META/MMA-TBB resin cement to bond orthodontic brackets. Angle Orthod. 2005;75(2):260.

19. Cehreli Z, Kecik D, Kocadereli I. Effect of self-etching primer and adhesive formulations on the shear bond strength of orthodontic brackets. Am J Orthod Dentofacial Orthop. 2005;127:573-9.

20. Bishara SE, Ostby AW, Laffoon JF, Waren J. Shear bond strength comparison of two adhesive systems following thermocycling. A new self-etch primer and a resin-modified glass ionomer. Angle Orthod. 2007;77:337-41.

21. American National Standards Institute and American Dental Association. Specification no. 27: resin-based filling materials. Chicago: American Dental Association; 1993

22. International Organization of Standardization. Dental materials: testing of adhesion to tooth structure. 2003. ISO/TS 11405.

23. Janda R, Roulet JF, Latta M, Rüttermann $\mathrm{S}$. The effects of thermocycling on the flexural strength and flexural modulus of modern resin-based filling materials. Dent Mater. 2006:22:812-7.

24. Labella R, Lambrechts P, Van Meerbeek B, Vanherle G. Polymerization shrinkage and elasticity of flowable composites and filled adhesives. Dent Mater. 1999;15:128-37.

25. Katona TR, Long RW. Effect of loading mode on bond strength of orthodontic brackets bonded with 2 systems. Am J Orthod Dentofacial Orthop. 2006:129:60-4.

26. Özcan M, Vallittu PK, Peltomäki T, Huysmans M, Kalk W. Bonding polycarbonate brackets to ceramic: effects of substrate treatment on bond strength. Am J Orthod Dentofacial Orthop. 2004;126:220-7.

27. Reynolds IR. A review of direct orthodontic bonding. $\mathrm{Br} J$ Orthodont. 1975;2:171-8.

28. Pandis N, Eliades T. A comparative in vivo assessment of the long-term failure rate of 2 self-etching primers. Am J Orthod Dentofacial Orthop. 2005; 128:96-8.

29. dos Santos JE, Quioca J, Loguercio AD, Reis A. Six-month bracket survival with a self-etch adhesive. Angle Orthod. 2006;76(5):863.

30. Aljubouri YD, Millett DT, Gilmour WH. Six and 12 months' evaluation of a self-etching primer versus two-stage etch and prime for orthodontic bonding: a randomized clinical trial. Eur J Orthod. 2004;26:565-71.

31. Ireland AJ, Knight $H$, Sherriff M. An in vivo investigation into bond failure rates with a new self-etching primer system. Am J Orthod Dentofacial Orthop. 2003;124:323-6.

32. Peutzfeldt A, Roulet JF. Restorative materials for the direct technique in: adhesion the silent revolution in dentistry. 1st ed. Chicago: Quintessence Publishing Co. Inc; 2000. Chap5:61-80

33. Wang L, D'Alpino PH, Lopes LG, Pereira JC. Mechanical properties of dental restorative materials: relative contribution of laboratory tests. J Appl Oral Sci. 2003;11:162-7. 
34. Sudsangiam S, van Noort R. Do dentin bond strength tests serve a useful purpose? J Adhes Dent. 1999;1(1):57.

35. Kemp-Scholte CM, Davidson CL. Marginal sealing of curing contraction gaps in class $V$ composite resin restorations. J Dent Res. 1988;67:841-5.

36. Xia Y, Zhang F, Xie H, Gu N. Nanoparticle-reinforced resin-based dental composites. J Dent. 2008;36:450-5.

37. Garcia-Contreras R, Scougall-Vilchis RJ, Contreras-Bulnes R, Sakagami H, Morales-Luckie RA, Nakajima H. Mechanical, antibacterial and bond strength properties of nano-titanium-enriched glass ionomer cement. J Appl Oral Sci. 2015;23:321-8.

38. Sun L, Gibson R, Gordaninejad F, Suhr J. Energy absorption capability of nanocomposites: a review. CompSci Tech. 2009;69:2392-409.

39. Liu X, Han Y, Gao G, Li Z, Liu F. Effect of silane coupling agent on the mechanical, thermal properties and morphology of tremolite/PA1010 composites. Chinese J Polymer Sci. 2008:26:255-62.

40. Eslamian L, Borzabadi-Farahani A, Mousavi N, Ghasemi A. A comparative study of shear bond strength between metal and ceramic brackets and artificially aged composite restorations using different surface treatments. Eur J Orthod. 2012;34(5):610.

Submit your next manuscript to BioMed Central and we will help you at every step:

- We accept pre-submission inquiries

- Our selector tool helps you to find the most relevant journal

- We provide round the clock customer support

- Convenient online submission

- Thorough peer review

- Inclusion in PubMed and all major indexing services

- Maximum visibility for your research

Submit your manuscript at www.biomedcentral.com/submit
Biomed Central 